\title{
Designer Molecular Probes for Phosphonium Ionic Liquids
}

\author{
Robert Byrne, ${ }^{1}$ Simon Coleman, ${ }^{2}$ Simon Gallagher, ${ }^{1}$ and Dermot Diamond. ${ }^{1}$ \\ ${ }^{1}$ CLARITY: Centre for Sensor Web Technologies, National Centre for Sensor \\ Research, Dublin City University, Dublin 9, Ireland \\ ${ }^{2}$ Biomedical Diagnostics Institute, National Centre for Sensor Research, Dublin City \\ University, Dublin 9, Ireland
}

\section{Abstract}

Investigations into the extent of structuring present in phosphonium based ionic liquids were carried out using photochromic molecular probes. Three spiropyran derivatives containing hydroxyl (BSP-1), carboxylic acid (BSP-2) and aliphatic chain $\left(\mathrm{C}_{14} \mathrm{H}_{29}\right)$ (BSP-3) functional groups were analysed in a range of phosphonium based ionic liquids and their subsequent physico-chemical interactions were reported. It is believed that the functional groups locate the probe molecules into specific regions based upon the interaction of the functional groups with particular and defined regions of the ionic liquid. The existence of structuring resulted in varied thermodynamic, kinetic and solvatochromic parameters with responses directly related to the certain polar and non-polar domains. BSP-1 and BSP-2 were found to exhibit generally negative entropies of activation ranging from $-50 \mathrm{JK}^{-1} \mathrm{~mol}^{-1}$ to $-90 \mathrm{JK}^{-1} \mathrm{~mol}^{-1}$ implying relatively low solvent-solute interactions and possible anion interactions with the polar functional groups. Higher than expected activation energies of $60 \mathrm{~kJ} \cdot \mathrm{mol}^{-1}$ to $100 \mathrm{~kJ} . \mathrm{mol}^{-1}$ for polar probes maybe be due to functional groups competing with the charge sites of the MC form for solvent interaction thus reducing MC stabilisation effects. Differences in thermal relaxation rate constants $\left(2.5 \times 10^{-3} \mathrm{~s}^{-1}\right.$ in BSP-1 and $3 \times 10^{-4} \mathrm{~s}^{-1}$ in $\mathrm{BSP}-2$ in $\left.\left[\mathrm{P}_{6,6,6,14}\right][\mathrm{dbsa}]\right)$ implied that the polar probe systems were examining polar/charged regions but that each probe was examining slightly differing polar domains. BSP-3 entropies of activation were positive and between $30 \mathrm{JK}^{-1} \mathrm{~mol}^{-1}$ to $66 \mathrm{JK}^{-1} \mathrm{~mol}^{-1}$. The association of the non-polar functional group was believed to locate the spiropyran moiety to the interface of polar and non-polar regions and thus the thermal relaxation of the $\mathrm{MC}$ form resulted in solvent reorientation to accommodate the molecule as it reverted to its closed form. Slow rate constants in contrast to high activation energies $\left(5 \times 10^{-4} \mathrm{~s}^{-1}\right.$ and $111.91 \mathrm{~kJ}^{\mathrm{mol}}{ }^{-1}$ respectively, for 
BSP-3 in $\left.\left[\mathrm{P}_{6,6,6,14}\right][\mathrm{dbsa}]\right)$ may have been due to steric effects due to proposed cavity formation of the alkyl chains in phosphonium based IL structuring. 


\section{Introduction}

The study of ionic liquids has expanded to nearly all facets of science, from solar cell technology to biological sciences, separation/extraction chemistry to hydrogen storage. This novel class of solvents that consist of only ions have several distinct advantages over traditional solvents, such as negligible vapour pressure, high thermal stabilities, tunable viscosities, and both hydrophobic and hydrophilic natures. One can understand why ionic liquids are attracting the attention of scientists and engineers for use in a range of applications. However, it would seem from the growing number of publications in recent years, studying the physico-chemical interactions of ionic liquids with solutes that some fundamentally different chemical processes are observed within ionic liquids compared to traditional molecular solvents.

It has been argued that the solvent properties of ionic liquids may not be well accounted for by conventional macroscopic parameters like polarity and dielectric constant, which have been extensively used for molecular solvents. Some early characterisation of ionic liquids involved the use of a polarity scale based on solvatochromic probe dyes (Nile Red and Reichardts dye). ${ }^{1}$ Unfortunately, all ionic liquids studied appeared to have the same or similar properties, to that of moderately polar solvents. This was in stark contrast to their behaviour as reaction solvents since different ionic liquids produced very different products. These contradictory results do not invalidate the use of solvatochromic dyes for ionic liquid characterisation but more importantly inform us of the multiple solvation shells possible within ionic liquids. As we know, polar solutes will preferentially be solvated by polar solvents; therefore polar solvatochromic dyes will only observe their immediate polar environment, and do not observe the bulk molecular environment outside of their solvation shell, this could explain these contradictory results. Therefore, multiparameter scales such as the Kamlet-Taft system have been developed to account for multiple solvation interactions, this system is based upon Linear Solvation Energy Relationships composed of the complimentary scales of hydrogen bond acidity $(\alpha)$, hydrogen bond basicity $(\beta)$ and dipolarity/polarizability effects $\left(\pi^{*}\right){ }^{2,}{ }^{3}$ Many ionic liquid families have been characterised using the Kamlet-Taft system but caution 
must be taken on the reliability of this scale, as some discrepancies have been reported when using different dyes to measure the parameters.

Consequently, additional approaches are needed to help characterize the solvation properties of ionic liquids that can account for the multiple solvent-solute interactions possible. Time resolved fluorescence spectroscopy of PRODAN ${ }^{4}$ and other probe molecules have been carried out to study the dynamics of solvation in ionic liquids, ${ }^{5,6}$ it has been proposed that coumarin 153 is preferentially solvated by the cation via dipole relaxation. ${ }^{7}$ Iwata investigated the behaviour of 2 -aminoquinoline in several ionic liquids using similar techniques and found certain imidazolium ionic liquids to form complexes with 2 -aminoaquinoline. ${ }^{8}$ This led to the hypothesis that certain ionic liquids are capable of forming distinct structures. Linear and Nonlinear Raman spectroscopy showed evidence of imidazolium ionic liquids appearing homogeneous macroscopically, but heterogeneous microscopically in the nanometre scale. ${ }^{9}$ Molecular dynamics simulations have supported this view. ${ }^{10,11}$

Traditionally in sensor science, one develops a molecule to monitor a single parameter in its local environment, such as ion concentration. Recently, more functionalized molecular sensors have been synthesised to respond to multiple parameters, each by a different analytical technique. de Silva has pioneered this area of sensor science with his 'multiplexing sensor molecules', which correspond to nanosized robots that go to humanly inaccessible spaces, monitor its local environment and send information back to us. ${ }^{12}$

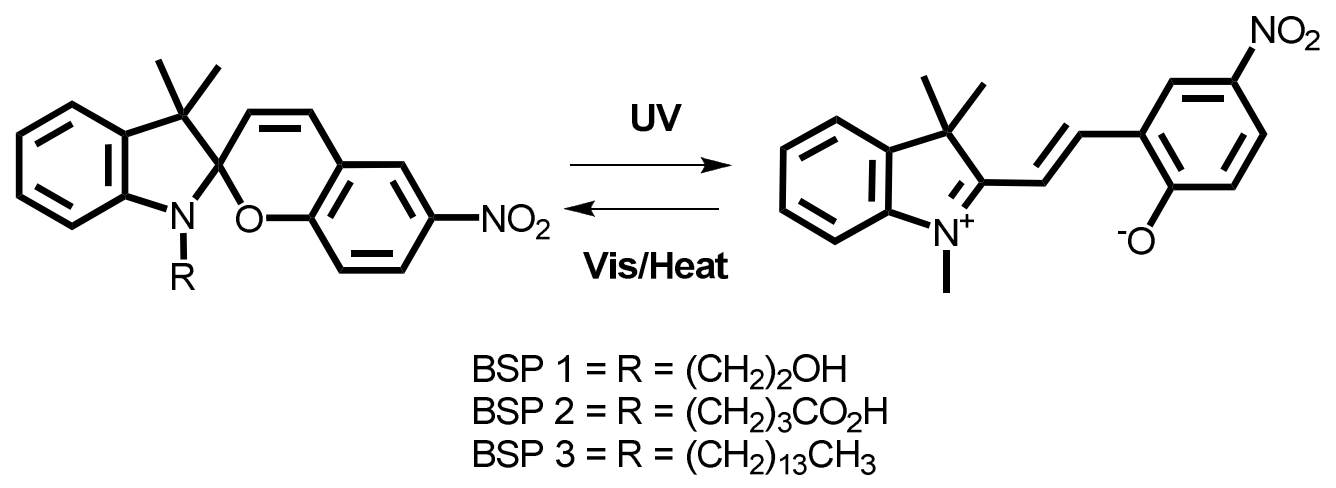

Figure 1. Photo and thermochromism of nitrobenzospiropyran (BSP, left) to the merocyanine (MC, right).

We recently reported the photo- and solvatochromic properties of nitrobenzospiropyran (BSP) in Ionic liquids containing the anion $\left[\right.$ NTf2] ${ }^{-13}$ BSP 
when exposed to UV light undergoes an isomerization wherein the spiro linkage is severed, resulting in the merocyanine isomer, a highly polar zwitterion that is coloured. The merocyanine thermally reverts back to the BSP isomer following first order kinetics, Figure 1. The BSP-MC isomerisation also exhibits properties similar to a multiplexing sensor, as it reveals a significant amount of information about its surrounding molecular environment: (i) at equilibrium an estimate of polarity can be calculated from the value $\mathrm{K}_{\mathrm{e}}$, the population of non-polar BSP versus the highly polar $\mathrm{MC},{ }^{14}$ (ii) the $\mathrm{MC}$ isomer exhibits a large negative solvatochromic shift with increasing polarity, ${ }^{15}$ (iii) the $\mathrm{MC}$ isomer possesses a large polarizable $\pi$-electron system, suitable for the registration of dispersion interaction, (iv) the phenolate oxygen on the MC exhibits a highly basic, electron pair donor, suitable for interaction with hydrogen bond donors and Lewis acids, an example is the coordination with the metal ion $\mathrm{Co}^{2+}$ and protons, ${ }^{16,17}$ also (v) the thermal isomerisation of MC to BSP is dependent on all of the above, an example is the interaction of amino acids at the complementary binding sites on the MC retarding the thermal back reaction. ${ }^{18-20} \mathrm{It}$ was found that the kinetics and thermodynamics of the BSP-MC equilibrium were sensitive to the nature of the cation in Ionic liquids, we also observed that the imidazolium cation can form a through-space orbital interaction with the $\mathrm{MC}$ isomer, rather than a simple electrostatic interaction, thus preventing the $\mathrm{MC}$ conversion back to the BSP. Wu et al reported similar interactions of imidazolium based Ionic liquids with BSP derivatives and in some cases negative photochromism was observed for BSP. ${ }^{21}$ We also studied the photochromic properties of BSP in phosphonium based Ionic liquids, it was found that a non-linear relationship between equilibrium constant $\left(\mathrm{K}_{\mathrm{e}}\right)$ and thermal isomerisation of MC to BSP (k) was observed; this contradicts what is expected for BSP in molecular solvents and suggests the isomers exhibit different molecular/solvation environments. ${ }^{22}$ Similar observations have been also found for the photochromic behaviour of spirooxazines in Ionic liquids. ${ }^{23}$

Wohl and Kuciauskas demonstrated the ability to control the position of BSP in a phospholipid bilayer by substituting various functional groups at the indole moiety of the BSP. They reported that the position of the BSP in the phospholipid bilayer was reflected in the thermal ring closing of the MC. Herein, we demonstrate a new type of multiplexing molecular probes that can be positioned in specific molecular environments. These probes can simultaneously monitor multiple parameters (cations, 
anions and polarity in this instance) by multiple optical properties (thermal degradation of merocyanine and solvatochromic wavelength shift, respectively).

\section{Experimental}

1-(2-hydroxyethyl)-3,3-dimethylindoline-6'-nitrobenzospiropyran (BSP-1) was purchased from TCI chemicals and used as received. BSP-2 and BSP-3 were

synthesised as reported. ${ }^{24,25}$ Anhydrous acetonitrile, ethanol and dichloromethane was purchased from Sigma Alrich and used without further purification. Tetradecyl(trihexyl)-phosphonium bis(trifluoromethylsulfonyl)imide $\left(\left[\mathrm{P}_{6,6,6,14}\right]\left[\mathrm{NTf}_{2}\right]\right)$, Tetradecyl(trihexyl)-phosphonium dicyanamide $\left(\left[\mathrm{P}_{6,6,6,14}\right][\mathrm{dca}]\right)$, Tetradecyl(trihexyl)-phosphonium dodecylbenzenesulfonate $\quad\left(\left[\mathrm{P}_{6,6,6,14}\right][\mathrm{dbsa}]\right)$, triisobutyl(methyl)phosphonium tosylate $\left(\left[\mathrm{P}_{1,4,4,4}\right][\right.$ tos $\left.]\right)$ were supplied by Cytec industries Tetradecyl(trihexyl)-phosphonium tris(pentafluoroethyl)trifluorophosphate $\left(\left[\mathrm{P}_{6,6,6,14}\right][\mathrm{FAP}]\right)$ was supplied by Merck. As reported previously, commercially available phosphonium based Ionic liquids contain traces of phosphines, $\mathrm{HCl}$ and water. Recognizing the sensitivity of molecular probe studies by spectroscopic methods, we followed the detailed purification method developed by Ramnial et al. ${ }^{26}$ The effect of cleaning can be seen from the UV-vis spectrum of $\left[\mathrm{P}_{6,6,6,14}\right][\mathrm{dbsa}]$ and $\left[\mathrm{P}_{6,6,6,14}\right][\mathrm{dca}]$ in ESI Figure 1 and 2, respectively. The yellow colour is removed from $\left[\mathrm{P}_{6,6,6,14}\right][\mathrm{dca}]$ as seen in the photograph, ESI Figure 3. All Ionic liquids were stored under reduced pressure until further use. All spectra were recorded on a UV-Vis-NIR Perkin-Elmer Lambda 900 spectrometer. The ultraviolet irradiation source was a BONDwand UV-365 nm obtained from Electrolite Corporation. The white light source was a Lumina obtained from Chiu Technical Corporation. Samples were irradiated at a distance of $5 \mathrm{~cm}$ for 60 seconds. Standard solutions of BSP derivatives were made up to $1 \times 10^{-4} \mathrm{M}$ in acetonitrile. $1 \mathrm{ml}$ of this solution was placed in a vial and the solvent removed by $\mathrm{N}_{2}$ stream. To this $1 \mathrm{ml}$ of the selected IL (Figure 2) was added to the vial and placed in sonicator for 10 minutes at $40^{\circ} \mathrm{C}$. Samples were stored under argon in the dark at $20^{\circ} \mathrm{C}$ for 15 hours before absorbance measurement was taken. The kinetic parameters of the MC thermal reversion to BSP were determined at each temperature by monitoring the disappearance of the $\mathrm{MC}$ at the $\lambda_{\max }$ after having removed the irradiating source. 
<smiles>CCCC[P+](C)(CCC)CCCC</smiles><smiles>CC(C)C[P+](C)(CC(C)C)CC(C)C</smiles><smiles>N#C[N]C#N</smiles><smiles>O=S(=O)([N-]S(=O)(=O)C(F)(F)F)C(F)(F)F</smiles>

$\left[\mathrm{NTf}_{2}\right]^{-}$<smiles>CCC(CC)c1ccc(S(=O)(=O)[O-])cc1</smiles>

$[\mathrm{dbsa}]^{-}$

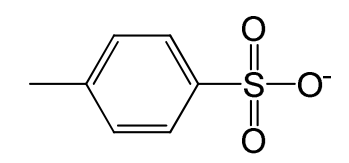

[tos]

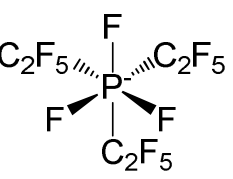

[FAP]

Figure 2. Molecular structures of Ionic liquids studied. Tetradecyl(trihexyl)-phosphonium $\left[\mathbf{P}_{6,6,6,14}\right]^{+}$, triisobutyl(methyl)phosphonium $\left[\mathbf{P}_{1,4,4,4}\right]^{+}$, bis(trifluoromethylsulfonyl)imide $\left[\mathrm{NTf}_{2}\right]^{-}$, dicyanamide dca $]^{-}$dodecylbenzenesulfonate [dbsa], tosylate [tos]", and tris(pentafluoroethyl)trifluorophosphate [FAP]".

\section{Results}

Controlling the position/solvation of a molecular probe in a complex system such as a micelle or phospholipid bilayer by modifying its chemical structure is very appealing, as one can monitor specific molecular environments on demand. ${ }^{12,}{ }^{27}$ It has been proposed that ionic liquids form specific structured molecular domains. ${ }^{10,}{ }^{11}$ One particular study by Pison et al investigates the solubility of fluorinated gases in trihexyltetradecylphosphonium bis(trifluoromethylsulfonyl)amide supported with molecular simulation calculations. ${ }^{28}$ It was found that unexpected solubility profiles of certain sized fluorinated gases could be explained by their location with respect to the solvents ions. Applying this train of thought to ionic liquids to seek out specific polar or non-polar domains is very exciting. In this study, we investigated the possibility of positioning BSP molecules in specific solvation environments within phosphonium based ionic liquids by synthetically modifying BSP derivatives and studying their spectrokinetic and thermodynamic properties. For example BSP-1 and 2 (see Figure 1) have polar appendages located at the indoline nitrogen, it is hoped that these BSP derivatives will embed themselves within a polar domain and report their locations (via solvatochromic shift of $\lambda_{\max }$ of MC isomer) and the specific and non-specific interactions it observes (via kinetic and thermodynamic parameters determining the MC thermal relaxation process). As it is envisaged, that BSP-3 will 
locate within non-polar regions and report on its immediate molecular environment, due to its non-polar appendage. The properties of the BSP derivatives in orhanic solvents will be used as a reference when comparing with Ionic liquids. To support and validate our experimental results, the solvatochromic probe Reichardt's dye 30 has been used as a solvent-dependent reference process to define empirically a solvent polarity scale, $\mathrm{E}_{\mathrm{T}}(30)$ scale. $^{29}$

\section{BSP-1 Hydroxyl derivative}

The physical, kinetic and thermodynamic properties of the BSP-1 are tabulated in Table 1. UV-vis absorption spectrum of BSP-1 at room temperature in organic solvents has two major bands with maxima in the UV and visible region; UV irradiation of BSP-1 results in an increase of absorbance in the visible region due to the formation of the MC isomer. This photochromic behaviour is also observed in the ionic liquids studied herein. The UV-vis absorption spectrum of the MC isomer in ethanol $\left(\lambda_{\max }=538 \mathrm{~nm}\right),\left[\mathrm{P}_{66614}\right][\mathrm{dbsa}]\left(\lambda_{\max }=560 \mathrm{~nm}\right)$, and $\left[\mathrm{P}_{66614}\right][\mathrm{dca}]\left(\lambda_{\max }=576\right.$ $\mathrm{nm})$ can be seen in Figure 3a, positive solvatochromism was also observed for the BSP-1 derivative. It must be noted that when plotting the MC $\lambda_{\max }$ and ET(30) values for the ionic liquids we did not observe a linear relationship (correlation coefficient, $\mathrm{R}^{2}=0.4827$ ), as observed in organic solvents, see ESI Figure 4. It is well known that, after removal of UV light, the predominant MC form generated will thermally isomerize back to its equilibrium state; this decay in absorbance should follow first order kinetics, ${ }^{14}$ as it does in molecular solvents. First-order rate constants for the thermal relaxation of $\mathrm{MC}$ were determined by plotting $\ln \left(\mathrm{A}_{t} / \mathrm{A}_{0}\right)$ vs. time. Examples are shown for ethanol, $\left[\mathrm{P}_{6,6,6,14}\right][\mathrm{dca}]$, and $\left[\mathrm{P}_{66614}\right][\mathrm{dbsa}]$ in Figure $3 \mathrm{~b}$. Surprisingly, the longest MC lifetime was found to be in $\left[\mathrm{P}_{66614}\right][\mathrm{FAP}]$ (3333 seconds), this is was unexpected, according to the $\mathrm{E}_{\mathrm{T}}(30)$ scale it should have the least polar property of the all the ionic liquids studied. This result further indicates that the $\mathrm{E}_{\mathrm{T}}(30)$ scale cannot be solely trusted when accounting for polarity in ionic liquids. Furthermore, it would appear that the MC isomer for the BSP-1 derivative in general has shorter lifetimes in comparison to the BSP (where $\mathrm{R}=\mathrm{CH}_{3}$ ) studied previously, lifetime of MC (BSP-1) isomer in $\left[\mathrm{P}_{1444}\right]\left[\right.$ tos] is reduced by over $60 \% .^{22}$ This result is not what we expected, as we anticipated longer lifetimes due to the more polar hydroxyl group locating itself in polar regions. A linear correlation between $\mathrm{MC}\left(\lambda_{\max }\right)$ and its thermal relaxation rate constant (k) was found for BSP-1 in the ionic liquids, see ESI Figure 5. This 
suggests that the BSP-1 molecule observes similar solvation environments, unlike the reported behaviour of BSP in phosphonium ionic liquids. ${ }^{22}$ Albeit, Wu et al reported for imidazolium ionic liquids that electrostatic interactions between the MC and the ionic liquids become the dominant ones in controlling the molecular environments of the MC isomer. These interactions may be counteracted by the interactions of the polar side group and the surrounding ionic liquid solvent molecules. This effect may result in less polar microenvironments for the $\mathrm{MC}$, which could result in faster thermal relaxation kinetics.

\begin{tabular}{|c|c|c|c|c|c|c|c|c|c|c|}
\hline \multirow[b]{2}{*}{ Solvent } & \multirow[b]{2}{*}{$\mathrm{E}_{\mathrm{T}} 30\left(\mathrm{kcal} \cdot \mathrm{mol}^{-1}\right)^{\mathrm{a}}$} & \multirow[b]{2}{*}{$\lambda_{\max } \mathrm{MC}(\mathrm{nm})^{\mathrm{b}}$} & \multirow[b]{2}{*}{$\mathrm{k}\left(\mathrm{s}^{-1}\right)^{\mathrm{c}}$} & \multirow[b]{2}{*}{$1 / \mathrm{k}(\mathrm{s})$} & \multicolumn{2}{|c|}{ Arrhenius } & \multicolumn{4}{|c|}{ Eyring } \\
\hline & & & & & $\mathrm{E}_{\mathrm{a}}\left(\mathrm{kj} \cdot \mathrm{mol}^{-1}\right)$ & $A\left(s^{-1}\right)$ & $\Delta \mathrm{H}^{\ddagger} \mathrm{kj} \cdot \mathrm{mol}^{-1}$ & $\Delta \mathrm{S}^{\ddagger} \mathrm{J} \cdot \mathrm{K}^{-1} \cdot \mathrm{mol}^{-1}$ & $\Delta \mathrm{G}^{\ddagger} \mathrm{kj} \cdot \mathrm{mol}^{-1}$ & \\
\hline$\left[\mathrm{P}_{1444}\right][$ tos $]$ & 48.2 & 564 & $1.60 \mathrm{E}-03$ & 625 & 62.71 & $2.37 \mathrm{E}+08$ & 60.11 & -93.31 & 87.45 & 2. \\
\hline$\left[\mathrm{P}_{66614}\right][\mathrm{dbsa}]$ & 46.6 & 576 & $2.50 \mathrm{E}-03$ & 400 & 72.15 & $1.83 \mathrm{E}+10$ & 69.64 & -56.90 & 86.31 & 4. \\
\hline$\left[\mathrm{P}_{66614}\right]\left[\mathrm{NTf} \mathrm{f}_{2}\right]$ & 47.9 & 565 & $9.00 \mathrm{E}-04$ & 1111 & 92.02 & $1.30 \mathrm{E}+13$ & 89.42 & -2.54 & 90.17 & 3. \\
\hline$\left[\mathrm{P}_{66614}\right][\mathrm{dca}]$ & 46.1 & 568 & $1.20 \mathrm{E}-03$ & 833 & 75.59 & $3.79 \mathrm{E}+10$ & 73.00 & -51.09 & 87.97 & 1. \\
\hline$\left[\mathrm{P}_{66614}\right][\mathrm{FAP}]$ & 48 & 557 & $3.00 \mathrm{E}-04$ & 3333 & 92.43 & $9.82 \mathrm{E}+12$ & 89.84 & -4.90 & 91.27 & 4. \\
\hline Ethanol & 51.8 & 538 & $4.00 \mathrm{E}-04$ & 2500 & 65.27 & $2.04 \mathrm{E}+09$ & 62.84 & -92.55 & 89.96 & 6. \\
\hline Acetonitrile & 45.5 & 560 & $1.00 \mathrm{E}-03$ & 1000 & 94.23 & $6.74 \mathrm{E}+13$ & 91.80 & 11.66 & 88.38 & 1. \\
\hline Dichloromethane & 40.6 & 576 & $1.80 \mathrm{E}-03$ & 556 & 97.28 & $4.44 \mathrm{E}+14$ & 94.84 & 28.00 & 86.64 & 2. \\
\hline
\end{tabular}

${ }^{\mathrm{a}} \mathrm{E} \mathrm{T}(30)$ values are from the literature.

${ }^{b}$ Merocyanine $\lambda_{\max }$ measured after 1 min UV light.

${ }^{c}$ Thermal relaxation rate constant calculated from plotting $\ln \left(A_{t} / A_{0}\right)$ vs. time where $k=$ slope.

Table 1. Photo-physical constants of BSP-1 and $\mathbf{E}_{\mathrm{T}}(\mathbf{3 0})$ values of various phosphonium based Ionic liquids and organic solvents. (BSP and Reichardt's dye 30 concentration $10^{-4} \mathrm{M}$ ). All measurements carried out at $293 \mathrm{~K}$. 
(a)

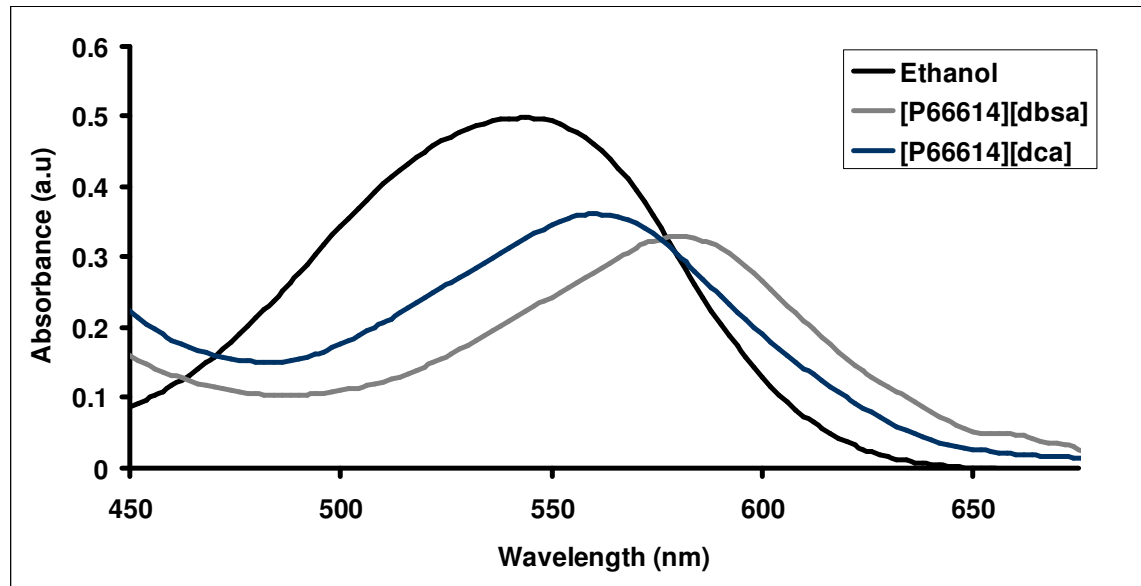

(b)

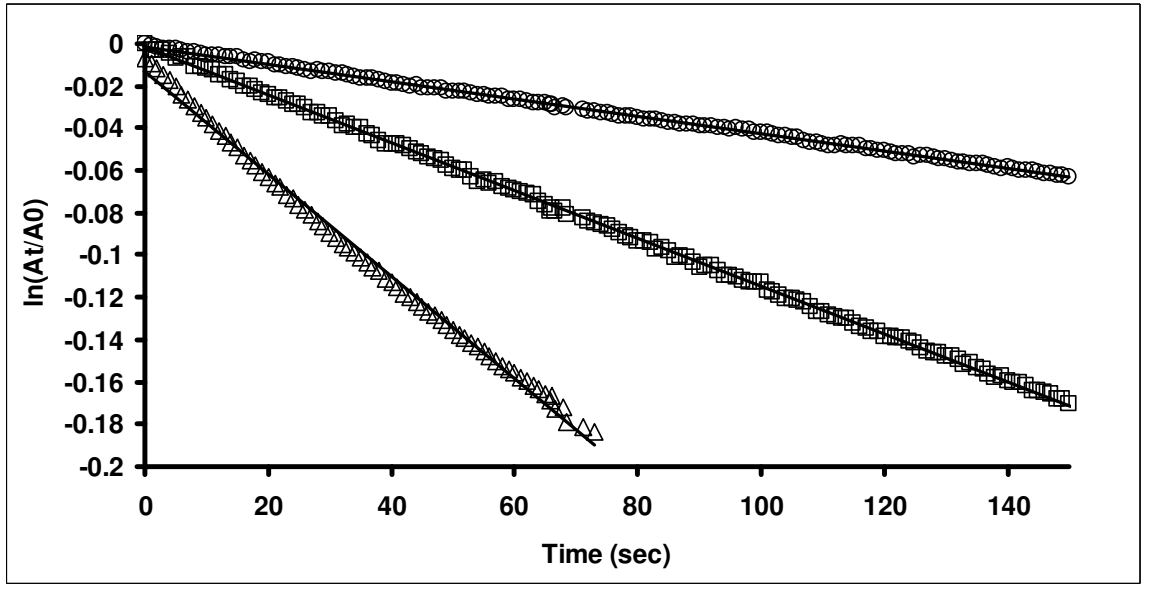

Figure 3. (a) Absorption spectra of $10^{-4} \mathrm{M}$ solutions of BSP-1 in ethanol, $\left[\mathbf{P}_{66614}\right][\mathrm{dbsa}]$, and $\left[\mathbf{P}_{66614}\right][\mathrm{dca}]$ when irradiated with UV light $(365 \mathrm{~nm})$ for 60 seconds. (b) Thermal relaxation of MC isomer in ethanol $\left(\circ, \mathrm{k}^{-1}=4 \times 10^{-4}\right),\left[\mathrm{P}_{66614}\right][\mathrm{dca}]\left(\square, \mathrm{k}^{-1}=1.2 \times 10^{-3}\right)$ and $\left[\mathrm{P}_{66614}\right][\mathrm{dbsa}]\left(\Delta, \mathrm{k}^{-1}=\right.$ $\left.2.5 \times 10^{-3}\right)$. All measurements at $293 \mathrm{~K}$.

The results described for photochromic behaviour refer to room temperature (293 K), but the rate of thermal relaxation depends strongly on temperature. The linear temperature dependence of the rate of thermal relaxation of $\mathrm{MC}$ in the ionic liquids studied were plotted using eqn (2).

$$
\begin{gathered}
\ln \mathrm{k}=\mathrm{E}_{\mathrm{a}} / \mathrm{RT}+\ln \mathrm{A}(2) \\
\ln (\mathrm{k} / \mathrm{T})=-\Delta \mathrm{H}^{\ddagger} / \mathrm{RT}+\ln \left(\mathrm{k}_{\mathrm{B}} / \mathrm{h}\right)+\Delta \mathrm{S}^{\ddagger} / \mathrm{R}(3)
\end{gathered}
$$

where $\mathrm{R}=$ gas constant, $\mathrm{h}=$ Planck's constant, and $\mathrm{k}_{\mathrm{B}}=$ Boltzmann constant.

Plots of $\ln \mathrm{k}$ vs. 1/T are shown in Fig. 5 for thermal relaxation of $\mathrm{MC}$ in $\left[\mathrm{P}_{6,6,6,14}\right][\mathrm{NTf} 2],\left[\mathrm{P}_{6,6,6,14}\right][\mathrm{dca}],\left[\mathrm{P}_{6,6,6,14}\right][\mathrm{FAP}]$ and $\left[\mathrm{P}_{1,4,4,4}\right][$ tos $]$. From the linear Arrhenius dependences in all cases, the values of activation energy $\left(\mathrm{E}_{\mathrm{a}}\right)$ and the pre- 
exponential factor are derived (Table 1). It has been noted from the literature for molecular solvents that $\mathrm{MC}$ thermal relaxation $\mathrm{E}_{\mathrm{a}}$ values range from 75 to $105 \mathrm{~kJ} \mathrm{~mol}^{-}$ ${ }^{1}$ with a tendency to be higher in polar solvents, ${ }^{14,30}$ it can be clearly seen that for BSP-1 that the activation energy for ethanol is very low at $65.27 \mathrm{~kJ} \mathrm{~mol}^{-1}$, this could be due to the hydroxyl group disrupting the expected intermolecular hydrogen bonding with the solvent system and the MC isomer, as mentioned above. The $\mathrm{E}_{\mathrm{a}}$ values for acetonitrile and dichloromethane are expected, 94.23 and $97.28 \mathrm{~kJ} \mathrm{~mol}^{-1}$. For the ionic liquids, $\left[\mathrm{P}_{1,4,4,4}\right][\mathrm{tos}]$ was found to have the lowest activation energy of $62.71 \mathrm{~kJ} \mathrm{~mol}^{-1}$. It was found that $\left[\mathrm{P}_{6,6,6,14}\right][\mathrm{NTf} 2]$ and $\left[\mathrm{P}_{6,6,6,14}\right][\mathrm{FAP}]$ had similar $\mathrm{E}_{\mathrm{a}}$ values, 92.02 and $92.43 \mathrm{~kJ} \mathrm{~mol}^{-1}$, respectively. This would indicate that the MC thermal relaxation process in $\left[\mathrm{P}_{6,6,6,14}\right][\mathrm{NTf} 2]$ and $\left[\mathrm{P}_{6,6,6,14}\right][\mathrm{FAP}]$ are strongly dependent on temperature.

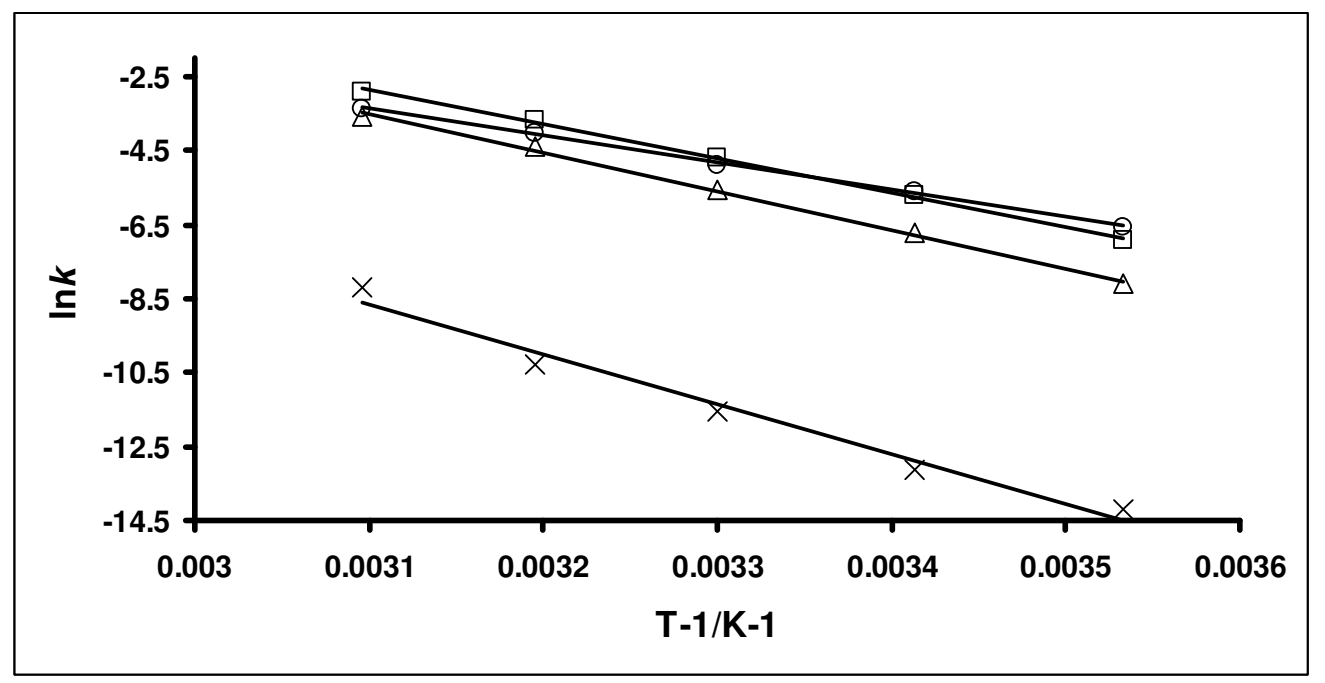

Figure 4. Arrhenius plot for the thermal relaxation of $M C(B S P-1)$ in $\left[P_{6,6,6,14}\right][N T f 2](X)$, $\left[\mathbf{P}_{6,6,6,14}\right][$ dca $](\square),\left[\mathbf{P}_{6,6,6,14}\right][$ FAP $](\Delta)$ and $\left[\mathbf{P}_{1,4,4,4}\right][$ tos $](\square)$ after 60 seconds UV irradiation. BSP concentration $1 \times 10^{-4} \mathrm{M}$ (correlation coefficients $\left.>0.98\right)$.

Using Eyring's transition state theory (eqn (3)), one can derive activation thermodynamic parameters such as $\Delta \mathrm{S}^{\ddagger}$ (entropy of activation), $\Delta \mathrm{H}^{\ddagger}$ (enthalpy of activation) and $\Delta \mathrm{G}^{\ddagger}$ (Gibbs energy of activation) for the thermal relaxation of MC, these are shown in Table 1. Moreover, transition state theory gives a satisfactory interpretation of orientation and solvent effects, since it interprets these in terms of entropy changes when the molecules come together. Since, the BSP-MC equilibrium is almost isoentropic, the consequence of balance between two opposite contributions to $\Delta \mathrm{S}^{0}$ : a positive contribution, which is related to the increased torsional freedom in 
the $\mathrm{MC}$ isomer, and a negative contribution, which is due to solvent reorientation around the more polar MC form. ${ }^{31}$ As expected, the experimental activation entropies $\left(\Delta S^{\dagger}\right)$ found for $\mathrm{MC}$ in the ionic liquids studied were significantly negative (e.g. $\left[\mathrm{P}_{1,4,4,4}\right][\mathrm{tos}] \Delta \mathrm{S}^{\ddagger}=-93.31 \mathrm{JK}^{-1} \mathrm{~mol}^{-1}$ and $\left.\left[\mathrm{P}_{6,6,6,11}\right][\mathrm{dca}] \Delta \mathrm{S}^{\ddagger}=-51.09 \mathrm{JK}^{-1} \mathrm{~mol}^{-1}\right)$, indicating a transition state with a more constrained structure than that of the MC isomer and more polar than the BSP-1 isomer, likely the result of electrostatic interactions with the charged groups. Albeit, it was observed that $\left[\mathrm{P}_{1,4,4,4}\right][\operatorname{tos}]$ had the smallest thermal relaxation $\mathrm{E}_{\mathrm{a}}$ and $\Delta \mathrm{H}^{\ddagger}$ values of $62 \mathrm{~kJ} \mathrm{~mol}^{-1}$ and $66 \mathrm{~kJ} \mathrm{~mol}^{-1}$, respectively. Similar results where also found for photomerocyanines in $\left[\mathrm{P}_{1,4,4,4}\right][\mathrm{tos}]{ }^{22}$ Photochromic materials with such a low thermal relaxation $\mathrm{E}_{\mathrm{a}}$ would be desirable for many applications as they don't have a large temperature dependence on colourability. Small frequency factors $\left(10^{8}-10^{10} \mathrm{~s}^{-1}\right)$ are associated with negative activation energies with respect to photochromic dyes. ${ }^{31}$ For $\left[\mathrm{P}_{6,6,6,14}\right][\mathrm{NTf} 2]$ and $\left[\mathrm{P}_{6,6,6,14}\right][\mathrm{FAP}]$, it would appear form their relatively longer $\mathbf{M C}$ lifetimes at $293 \mathrm{~K}$, that the MC is more solvated but from the thermodynamic data it would seem that the MC thermal relaxation process is strongly dependent on temperature. This would indicate that the energetic factor dominates over the entropic contribution at lower temperatures, this reflects the near zero $\Delta S^{\ddagger}$ values seen in Table 1 . At the outset, it was anticipated that the more polar BSP-1 derivative would associate itself with a polar domain resulting in a higher degree of solvation for the photo-induced MC isomer, see Figure 5. The thermodynamic parameters calculated in $\left[\mathrm{P}_{1,4,4,4}\right]$ tos], $\left[\mathrm{P}_{6,6,6,14}\right][\mathrm{dca}]$ and $\left[\mathrm{P}_{6,6,6,14}\right][\mathrm{dbsa}]$, show the $\mathbf{M C}$ isomer observes an increase in molecular interactions compared to the BSP-1 isomer (negative entropic contribution), indicating the polar side chain has influenced the position of the probe molecule within the ionic liquid compared to what is observed in acetonitrile and dichloromethane. 


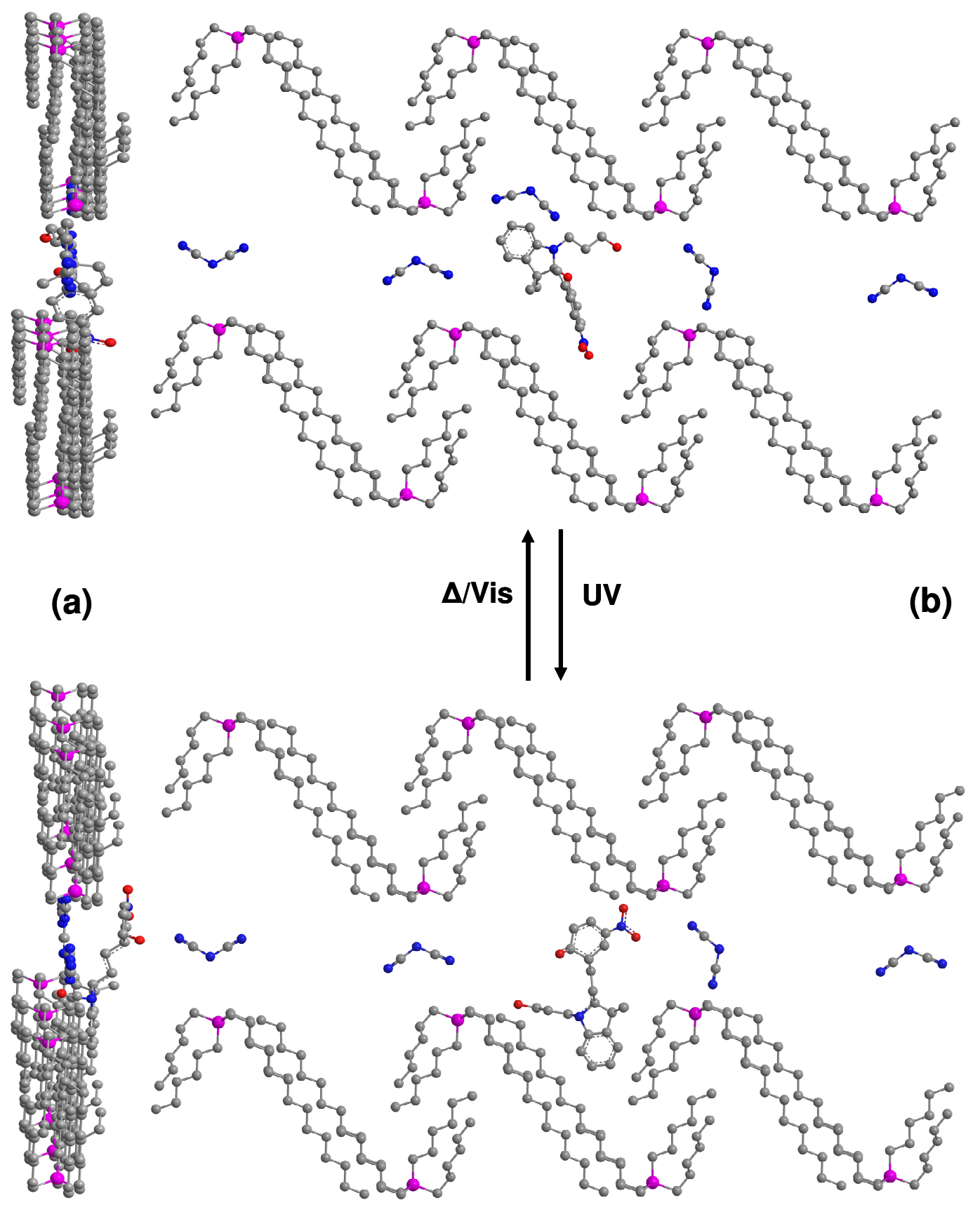

Figure 5. Schematic representation of BSP-1 photoinduced isomerisation to MC isomer in $\left[P_{6,6,6,14}\right][\mathrm{dca}]$. Isomerisation of BSP-1 to MC does not have a significant effect on surrounding polar environment as seen in experimental results. (a) displays cross section of segment of ionic liquid containing BSP-1. (b) top down view of same segment. 


\section{BSP-2 Carboxylic acid derivative}

The physical, kinetic and thermodynamic properties of the carboxylic acid derivative,

BSP-2, in phosphonium ionic liquids and organic solvents are tabulated in Table 2.

The addition of a carboxylic acid functional group adds a polar group to the molecule (similar to that of BSP-1) which is expected to enhance the intermolecular interactions such as hydrogen bonding. Analysis of kinetic and thermodynamic parameters in organic solvents provided results which agreed with established trends for photochromic spirocyclic compounds whereby increasing kinetics is expected with decreasing solvent polarity. The UV-vis absorption spectrum of the MC isomer in ethanol $\left(\lambda_{\max }=546 \mathrm{~nm}\right),\left[\mathrm{P}_{66614}\right][\mathrm{dbsa}]\left(\lambda_{\max }=579 \mathrm{~nm}\right)$, and $\left[\mathrm{P}_{66614}\right][\mathrm{dca}]\left(\lambda_{\max }=\right.$ $569 \mathrm{~nm}$ ) can be seen in Figure 6a, positive solvatochromism was also observed for the BSP-2 derivative. It must be noted that when plotting the $M C \lambda_{\max }$ and $\mathrm{E}_{\mathrm{T}}(30)$ values for the ionic liquids we did not observe a linear relationship. For BSP-2 it was found that dichloromethane provided the media for the most efficient thermal relaxation of MC isomer with a rate constant of $8 \times 10^{-4} \mathrm{~s}^{-1}$. This value was double that of acetonitrile $\left(4 \times 10^{-4} \mathrm{~s}^{-1}\right)$ and four times faster than ethanol $\left(2 \times 10^{-4} \mathrm{~s}^{-1}\right)$. First-order plots for the thermal relaxation of $\mathrm{MC}$ are shown for ethanol, $\left[\mathrm{P}_{6,6,6,14}\right][\mathrm{dca}]$, and $\left[\mathrm{P}_{66614}\right][\mathrm{dbsa}]$ in Figure 6b.

\begin{tabular}{|c|c|c|c|c|c|c|c|c|c|c|}
\hline \multirow[b]{2}{*}{ Solvent } & \multirow[b]{2}{*}{$\mathrm{ET}_{30}\left(\mathrm{kcal} \cdot \mathrm{mol}^{-1}\right)$} & \multirow[b]{2}{*}{$\lambda_{\max } M C(n m)$} & \multirow[b]{2}{*}{$\mathrm{k}\left(\mathrm{s}^{-1}\right)$} & \multirow[b]{2}{*}{$1 / \mathrm{k}(\mathrm{s})$} & \multicolumn{2}{|c|}{ Arrhenius } & \multicolumn{4}{|c|}{ Eyring } \\
\hline & & & & & $\mathrm{E}_{\mathrm{a}}\left(\mathrm{kj} \cdot \mathrm{mol}^{-1}\right)$ & $A\left(s^{-1}\right)$ & $\Delta \mathrm{H}^{\ddagger} \mathrm{kj} \cdot \mathrm{mol}^{-1}$ & $\Delta \mathrm{S}^{\ddagger} \mathrm{J} \cdot \mathrm{K}^{-1} \cdot \mathrm{mol}^{-1}$ & $\Delta \mathrm{G}^{\neq} \mathrm{kj} \cdot \mathrm{mol}^{-1}$ & 1 \\
\hline$\left[\mathrm{P}_{1444}\right][$ tos $]$ & 48.2 & 565 & $1.20 \mathrm{E}-03$ & 833 & 98.58 & $4.57 \mathrm{E}+14$ & 95.98 & 27.03 & 88.06 & 1.6 \\
\hline$\left[\mathrm{P}_{66614}\right][\mathrm{dbsa}]$ & 46.6 & 579 & $3.00 \mathrm{E}-04$ & 3333 & 84.28 & $1.36 \mathrm{E}+10$ & 73.91 & -59.50 & 91.34 & 4.9 \\
\hline$\left[\mathrm{P}_{66614}\right]\left[\mathrm{NTf}_{2}\right]$ & 47.9 & 560 & 2.30E-03 & 435 & 94.32 & $1.77 \mathrm{E}+14$ & 88.25 & 9.24 & 85.54 & 3.7 \\
\hline$\left[\mathrm{P}_{66614}\right][\mathrm{dca}]$ & 46.1 & 569 & $6.00 \mathrm{E}-04$ & 1667 & 80.28 & $5.65 \mathrm{E}+10$ & 84.28 & -26.79 & 92.13 & 8.1 \\
\hline$\left[\mathrm{P}_{66614}\right][\mathrm{FAP}]$ & 48 & 555 & $1.00 \mathrm{E}-04$ & 10000 & 79.33 & $1.49 \mathrm{E}+10$ & 76.73 & -59.24 & 94.09 & 1.6 \\
\hline Ethanol & 51.8 & 546 & $2.00 \mathrm{E}-04$ & 5000 & 105.35 & $1.33 \mathrm{E}+15$ & 102.92 & 36.42 & 92.24 & 3.2 \\
\hline Acetonitrile & 45.5 & 548 & $4.00 \mathrm{E}-04$ & 2500 & 112.27 & $1.17 \mathrm{E}+17$ & 109.83 & 73.73 & 88.23 & 1.6 \\
\hline Dichloromethane & 40.6 & 552 & $8.00 \mathrm{E}-04$ & 1250 & 105.50 & $5.50 \mathrm{E}+15$ & 103.06 & 48.24 & 88.93 & $1.3^{\circ}$ \\
\hline
\end{tabular}

Table 2. Photo-physical constants of $\mathrm{BSP}-2$ and $\mathrm{E}_{\mathrm{T}}(30)$ values of various phosphonium based Ionic liquids and organic solvents. (BSP and Reichardt's dye 30 concentration $10^{-4} \mathrm{M}$ ). All measurements carried out at $293 \mathrm{~K}$. 
(a)

(b)
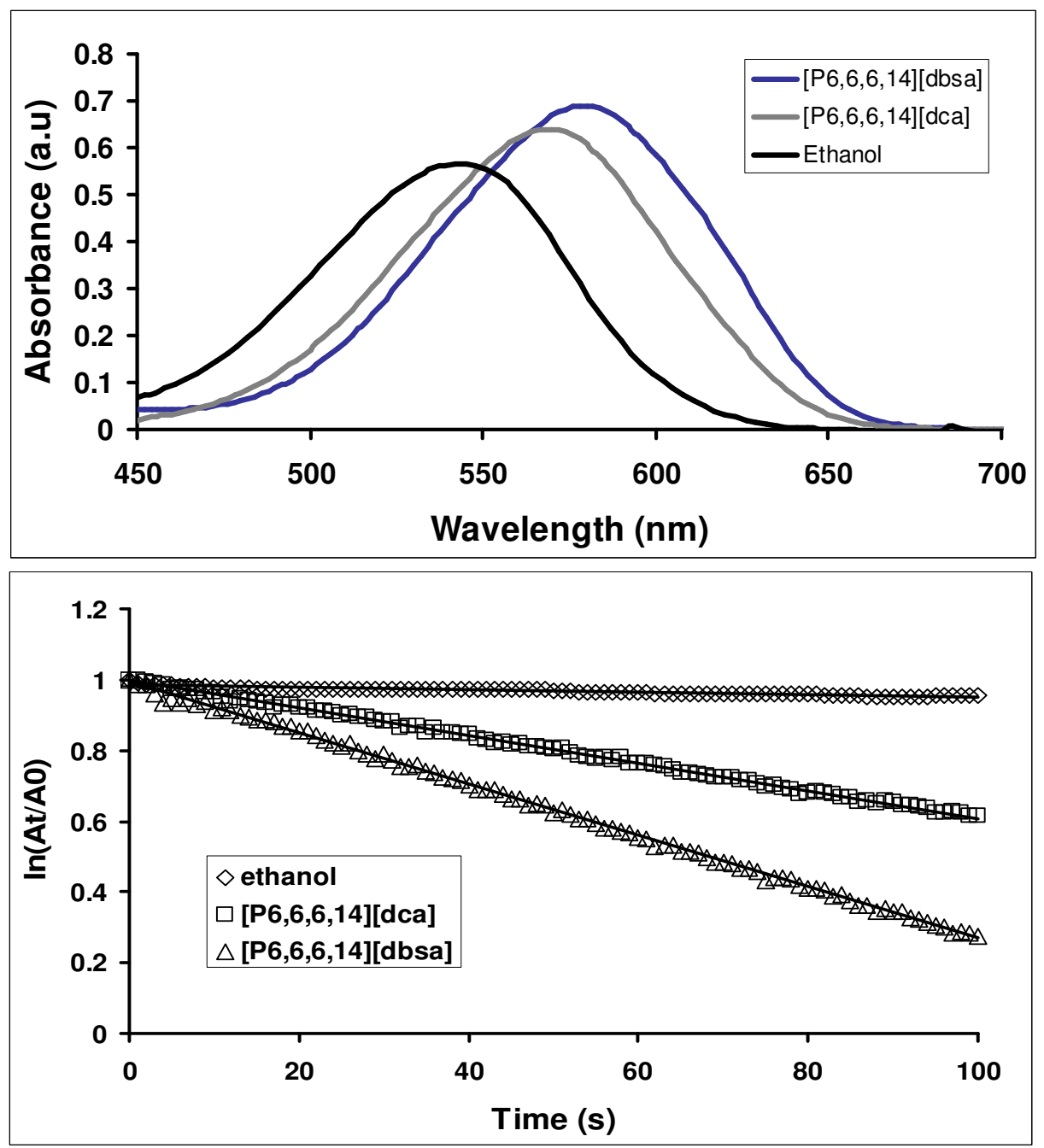

Figure 6. (a) Absorption spectra of $10^{-4} \mathrm{M}$ solutions of BSP-2 in ethanol, [ $\left.\mathrm{P}_{66614}\right][\mathrm{dbsa}]$, and $\left[P_{66614}\right][$ dca] when irradiated with $U V$ light $(365 \mathrm{~nm})$ for 60 seconds. (b) Thermal relaxation of MC isomer in ethanol $\left(\diamond, \mathrm{k}^{-1}=2 \times 10^{-4}\right),\left[\mathrm{P}_{66614}\right][\mathrm{dca}]\left(\square, \mathrm{k}^{-1}=6 \times 10^{-4}\right)$ and $\left[\mathrm{P}_{66614}\right][\mathrm{dbsa}]\left(\Delta, \mathrm{k}^{-1}=3\right.$ $\left.\times 10^{-4}\right)$. All measurements at $293 \mathrm{~K}$.

A correlation was found between kinetic and thermodynamic parameters for three phosphonium based ionic liquids; $\left[\mathrm{P}_{6,6,6,14}\right][\mathrm{dbsa}]$, $\left[\mathrm{P}_{6,6,6,14}\right]$ [dca] and $\left[\mathrm{P}_{1,4,4,4}\right][$ tos]. Initial observations found that the established $\mathrm{E}_{\mathrm{T}}(30)$ polarity-kinetic relationship of molecular solvents was again not upheld. The rate of thermal relaxation depends strongly on temperature. The linear temperature dependence of the rate of thermal relaxation of MC in the ionic liquids studied were plotted, example shown in Figure 7. From the linear Arrhenius dependences in all cases, the values of activation energy $\left(E_{a}\right)$ and the pre-exponential factor are derived (Table 2). The organic solvents exhibit $\mathrm{MC}$ thermal relaxation $\mathrm{E}_{\mathrm{a}}$ values range from $105-112 \mathrm{~kJ} \mathrm{~mol}^{-1}$, these correlate 
well with literature values. ${ }^{14,}{ }^{30}$ For BSP-2 in ionic liquids, $\left[\mathrm{P}_{1,4,4,4}\right][$ tos] was found to have the highest activation energy of $98.58 \mathrm{~kJ} \mathrm{~mol}^{-1}$, this was in stark contrast to what was observed for BSP-1, were $\left[\mathrm{P}_{1,4,4,4}\right]\left[\right.$ tos] had the lowest $\mathrm{E}_{\mathrm{a}}$ (see Table 1). It was found that $\left[\mathrm{P}_{6,6,6,14}\right][\mathrm{dca}]$ and $\left[\mathrm{P}_{6,6,6,14}\right][\mathrm{FAP}]$ again had similar $\mathrm{E}_{\mathrm{a}}$ values (80.28 and $79.33 \mathrm{~kJ} \mathrm{~mol}^{-1}$, respectively) but significantly different to what was observed in BSP1.

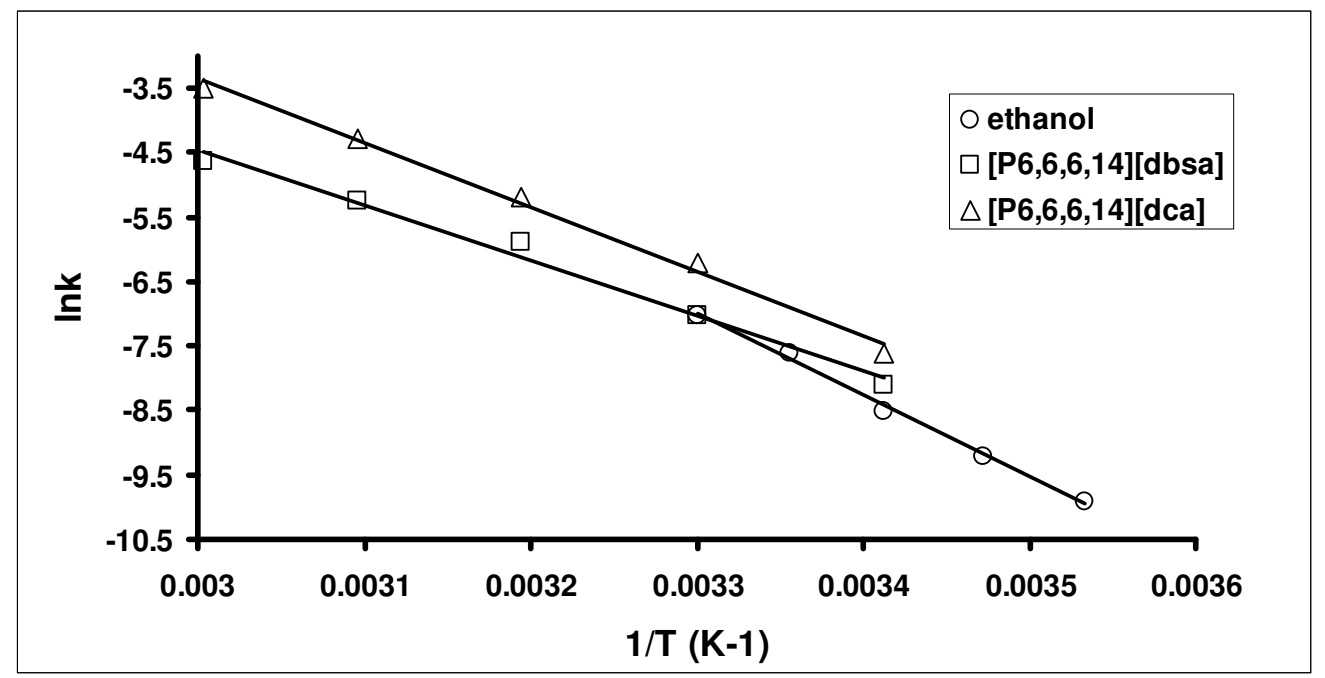

Figure 7. Arrhenius plot for the thermal relaxation of MC (BSP-2) in ethanol (o), $[P 6,6,6,14][\mathrm{dbsa}](\square)$, and $[P 6,6,6,14][\mathrm{dca}](\Delta)$ after 60 seconds $U V$ irradiation. BSP concentration $1 \times 10^{-4} \mathrm{M}$ (correlation coefficients $>0.98$ ).

Interestingly, $\left[\mathrm{P}_{6,6,6,14}\right][\mathrm{dbsa}]$, assumed to be a non-polar liquid due to the prevalence of multiple long alkyl chains, was found to exhibit rates of thermal relaxation between that of acetonitrile and ethanol with a rate of $3 \times 10^{-4} \mathrm{~s}^{-1}$. This rate would imply that the solvent system was somewhat polar, this was also observed by the thermodynamic parameters, $\left[\mathrm{P}_{6,6,6,14}\right][\mathrm{dbsa}]$ exhibits a significantly negative $\Delta \mathrm{S}^{\ddagger}$ of $-59.50 \mathrm{JK}^{-1} \mathrm{~mol}^{-1}$, indicating the transition state to be in a more polar environment. Such a negative value would imply that the solvent system is reorientating to accommodate the change in the probes molecular structure and charge (zwitterionic). This would explain the slow rates of thermal relaxation due to the stronger interactions between the ionic liquid and the $\mathrm{MC}$ isomer resulting in stabilisation.

Similar effects were observed for $\left[\mathrm{P}_{6,6,6,14}\right][\mathrm{dca}]$ with only an increase in the $\Delta \mathrm{S}^{\ddagger}$ values being of significance. The value was found to be higher than that of $\left[\mathrm{P}_{6,6,6,14}\right][\mathrm{dbsa}]$ at $-26.79 \mathrm{JK}^{-1} \mathrm{~mol}^{-1}$ which implied increased torsional $\mathrm{C}=\mathrm{C}$ rotation. 
Rates of thermal relaxation were more in line with that of non-polar solvent. This may be due to the fact that the $[\mathrm{dca}]^{-}$anion is smaller than that of [dbsa $]^{-}$anion which has a long alkyl chain attached. If we suggest that the [dbsa $]^{-}$alkyl chains enhance particular domain structure/size, then the reduced anion size should allow for less steric hindrance attributed by the anion resulting in faster thermal relaxation rate constants, as observed in Table 2. Examination of the addition of the BSP-2 to $\left[\mathrm{P}_{1,4,4,4}\right][$ tos] may confirm the above hypothesis of structuring, as the cation contains isobutyl side chains which differ from the other phosphonium cations which contained long alkyl chains, reducing van der Waals. The [tos] anion also has a shorter methyl group attached to it phenyl ring than that of the related [dbsa] anion. The reduced ion sizes and lack of mutual interactions would result in a more homogeneous liquid system. This was reflected in the $\Delta S^{\ddagger}$ value which is found to be positive at $27.03 \mathrm{JK}^{-1} \mathrm{~mol}^{-1}$ and close to that of ethanol $\left(36.42 \mathrm{JK}^{-1} \mathrm{~mol}^{-1}\right)$. Rates of thermal relaxation is found to be far larger than any other IL and is due to the fact that the ions are still generally non-polar in nature but the removal of steric hindrance now allows the probe dye to close freely with less restriction. 


\section{BSP-3 Tetradecane derivative}

A non-polar tetradecane BSP derivative (BSP-3) was added to the Ionic liquids to attempt to interact with the non-polar domains within the ionic liquid. It is believed that the non-polar side chain will interact with the alkyl chains of the phosphonium cations through van der Waals forces resulting in coordination of the BSP-3 molecule into specific regions of the IL. The physical, kinetic and thermodynamic properties of the BSP-3 are tabulated in Table 3. UV-vis absorption spectrum of BSP-3, showing photochromic behaviour, in $\left[\mathrm{P}_{1444}\right][\mathrm{tos}]\left(\lambda_{\max }=565 \mathrm{~nm}\right), \quad\left[\mathrm{P}_{66614}\right][\mathrm{dbsa}]\left(\lambda_{\max }=576\right.$ $\mathrm{nm})$ and dichloromethane $\left(\lambda_{\max }=579 \mathrm{~nm}\right)$ is shown in Figure 8a. Examination of the solvatochromic shifts reveals that the $\mathrm{MC}$ form of the compound is experiencing a non-polar region due to the appearance of positive solvatochromism and $\lambda_{\max }$ values in the region of $570 \mathrm{~nm}$ in Ionic liquids. These values were similar to that of dichloromethane which is known for its non-polar characteristics and minimal stabilisation of the MC isomer, resulting in short MC lifetimes. Again, the MC $\lambda_{\max }$ and $\mathrm{E}_{\mathrm{T}}(30)$ values for the ionic liquids did not exhibit a linear relationship.

Examination of rate constants however provided conflicting results based on the initial assumption that the ionic liquids exhibited non-polar characteristics due to positive solvatochromism. In fact, rates of thermal relaxation were found to be slower in ionic liquids than that of molecular solvents. For example $\left[\mathrm{P}_{66614}\right][\mathrm{dbsa}]$ had a rate of $5 \times 10^{-4} \mathrm{~s}^{-1}$ compared to that of acetonitrile at $1.3 \times 10^{-3} \mathrm{~s}^{-1}$. Such inconsistencies may be due to steric effects which are presented by the structuring of the cations with one another. As the BSP-3 molecule contains the tetradecane carbon chain, it would be expected to associate itself with the alkyl chains of the phosphonium cation such associations would locate the spiropyran fragment into particular non-polar cavities created by the aliphatic carbon chains. By surrounding the spiropyran moiety with non-polar chains the solvate-sensitive nitro group would 'sense' a non-polar domain which is in turn translated into the positive shifts observed in the UV-Vis characterisation of the MC isomer. The physical size of the MC and the constriction within this cavity results in reduced mobility and in turn slowed relaxation kinetics, as seen in Figure $8 b$. 
(a)

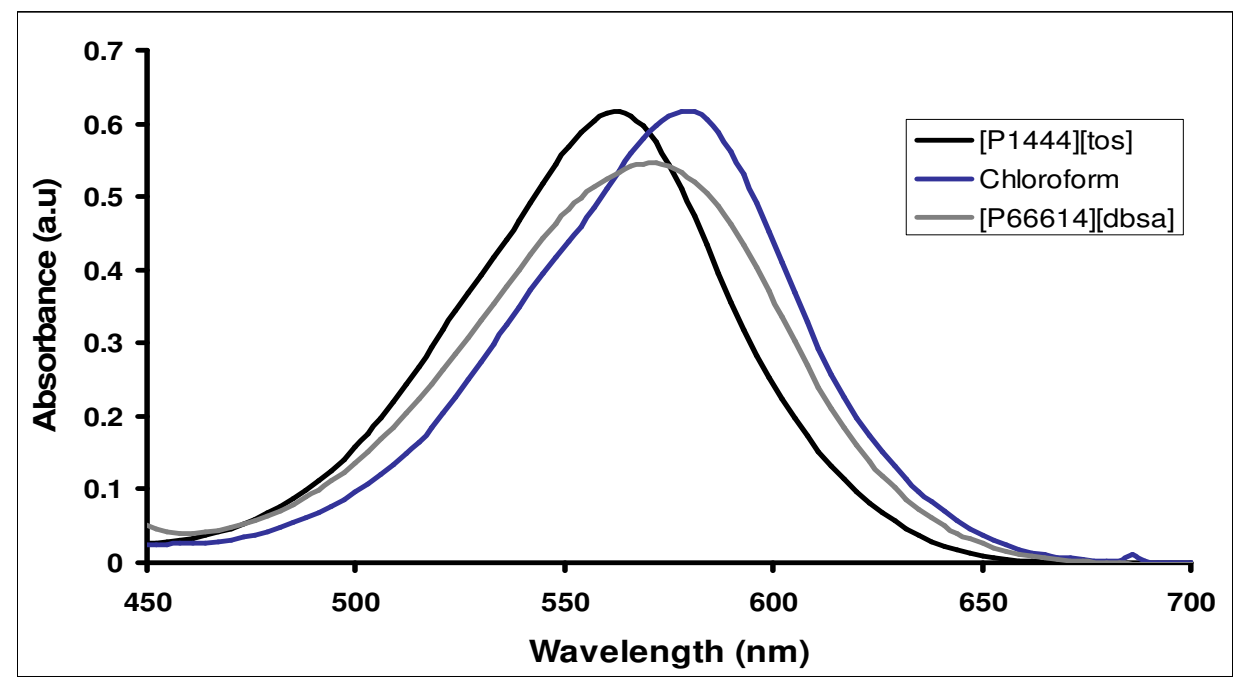

(b)

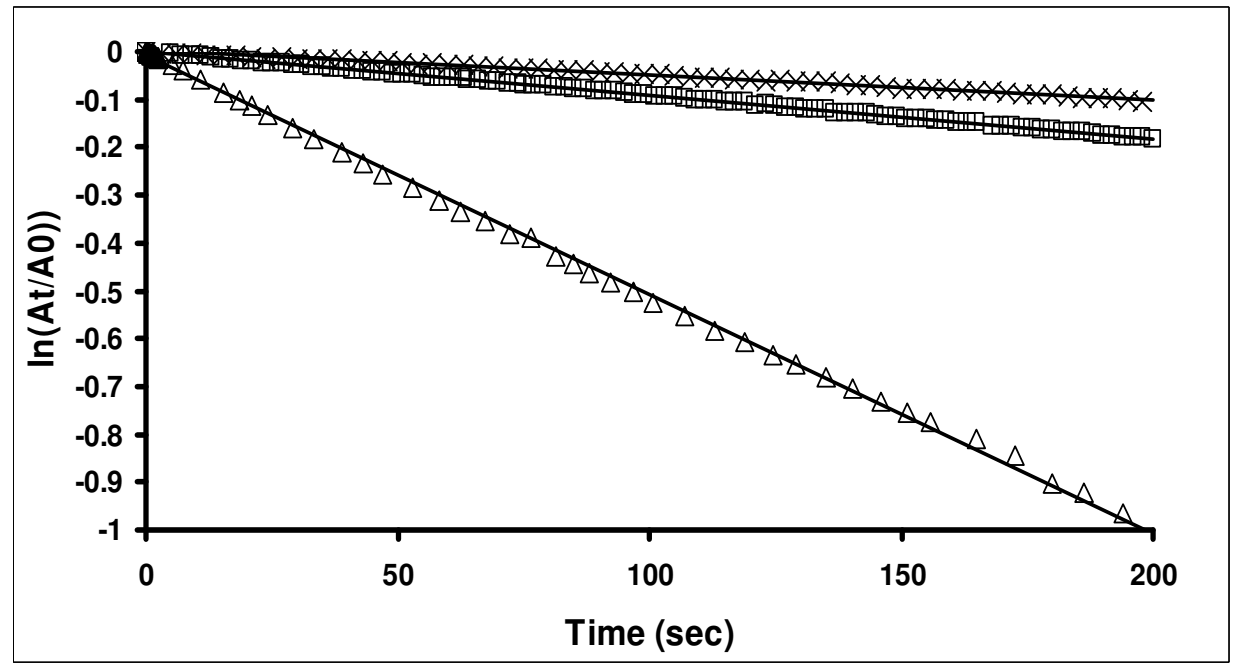

Figure 8. (a) Absorption spectra of $10^{-4} \mathrm{M}$ solutions of BSP-2 in [ $\left.\mathbf{P}_{1444}\right]\left[\right.$ tos], [ $\left.\mathbf{P}_{66614}\right][\mathrm{dbsa}]$, and dichloromethane when irradiated with UV light $(365 \mathrm{~nm})$ for 60 seconds. (b) Thermal relaxation of $\mathrm{MC}$ isomer in $\left[\mathrm{P}_{66614}\right][\mathrm{dbsa}]\left(\mathrm{X}, \mathrm{k}^{-1}=5 \times 10^{-4}\right),\left[\mathrm{P}_{66614}\right][\mathrm{dca}]\left(\square, \mathrm{k}^{-1}=9 \times 10^{-4}\right)$ and dichloromethane $\left(\Delta, \mathrm{k}^{-1}=4.7 \times 10^{-3}\right)$. All measurements at $293 \mathrm{~K}$.

If this hypothesis is correct, we should see very different thermodynamic contributions towards the thermal relaxation process, compared to the more polar derivatives BSP-1 and -2. Thermodynamic parameters appear to compliment this hypothesis with positive entropies of activation between $30 \mathrm{JK}^{-1} \cdot \mathrm{mol}^{-1}$ and $66 \mathrm{JK}^{-}$ ${ }^{1} . \mathrm{mol}^{-1}$ found in all Ionic liquids. As the MC relaxes back to its BSP isomer the nonpolar cavity must re-order around the now highly polar isomer, increasing entropy. See for Figure 9 a schematic illustration of this hypothesis. Activation energies were also found to be high with all Ionic liquids exhibiting values close to $100 \mathrm{~kJ}^{\mathrm{mol}}{ }^{-1}$ 
indicating that the reduced degree of torsional rotation produced a barrier to the relaxation of the MC form to its closed form.

\begin{tabular}{|c|c|c|c|c|c|c|c|c|c|c|}
\hline \multirow[b]{2}{*}{ Solvent } & \multirow[b]{2}{*}{$\mathrm{ET}_{30}\left(\mathrm{kcal}^{\mathrm{mol}}{ }^{-1}\right)$} & \multirow[b]{2}{*}{$\lambda_{\max } M C(\mathrm{~nm})$} & \multirow[b]{2}{*}{$\mathrm{k}\left(\mathrm{s}^{-1}\right)$} & \multirow[b]{2}{*}{$1 / \mathrm{k}(\mathrm{s})$} & \multicolumn{2}{|c|}{ Arrhenius } & \multicolumn{4}{|c|}{ Eyring } \\
\hline & & & & & $\mathrm{E}_{\mathrm{a}}\left(\mathrm{kj} \cdot \mathrm{mol}^{-1}\right)$ & $A\left(s^{-1}\right)$ & $\Delta \mathrm{H}^{\ddagger} \mathrm{kj} \cdot \mathrm{mol}^{-1}$ & $\Delta \mathrm{S}^{\ddagger} \mathrm{J} \cdot \mathrm{K}^{-1} \cdot \mathrm{mol}^{-1}$ & $\Delta \mathrm{G}^{\neq} \mathrm{kj} \cdot \mathrm{mol}^{-1}$ & \\
\hline$\left[\mathrm{P}_{1444}\right][$ tos $]$ & 48.2 & 565 & $6.00 \mathrm{E}-04$ & 1667 & 101.40 & $7.34 \mathrm{E}+14$ & 98.39 & 30.98 & 89.31 & 1.6 \\
\hline$\left[\mathrm{P}_{66614}\right][\mathrm{dbsa}]$ & 46.6 & 576 & $5.00 \mathrm{E}-04$ & 2000 & 111.91 & $5.38 \mathrm{E}+16$ & 109.32 & 66.67 & 89.78 & 8.1 \\
\hline$\left[\mathrm{P}_{66614}\right]\left[\mathrm{NTf}_{2}\right]$ & 47.9 & 575 & $8.00 \mathrm{E}-04$ & 1250 & 96.69 & $1.37 \mathrm{E}+14$ & 94.10 & 17.03 & 89.11 & 1.3 \\
\hline$\left[\mathrm{P}_{66614}\right][\mathrm{dca}]$ & 46.1 & 573 & $9.00 \mathrm{E}-04$ & 1111 & 97.52 & $2.21 \mathrm{E}+14$ & 94.93 & 20.98 & 88.78 & 1.4 \\
\hline$\left[\mathrm{P}_{66614}\right][\mathrm{FAP}]$ & 48 & 572 & $7.00 \mathrm{E}-04$ & 1429 & 94.79 & $6.56 \mathrm{E}+13$ & 92.20 & 10.89 & 89.01 & 1.1 \\
\hline Ethanol & 51.8 & 542 & $2.00 \mathrm{E}-04$ & 5000 & 105.74 & $2.18 \mathrm{E}+15$ & 103.30 & 41.03 & 91.28 & 6.5 \\
\hline Acetonitrile & 45.5 & 561 & $1.30 \mathrm{E}-03$ & 769 & 87.38 & $1.52 \mathrm{E}+13$ & 87.38 & -1.10 & 87.70 & 2.1 \\
\hline Dichloromethane & 40.6 & 579 & 4.70E-03 & 213 & 88.50 & $3.13 \mathrm{E}+13$ & 86.06 & 5.27 & 84.52 & 7. \\
\hline
\end{tabular}

Table 3. Photo-physical constants of $\mathrm{BSP} 3$ and $\mathrm{E}_{\mathrm{T}}(30)$ values of various phosphonium based Ionic liquids and organic solvents. (BSP and Reichardt's dye 30 concentration $10^{-4} \mathrm{M}$ ). All measurements

carried out at $293 \mathrm{~K}$. 
Figure 9. Schematic illustration of BSP-3 photoinduced isomerisation to $\mathrm{MC}$ isomer in $\left[P_{6,6,6,14}\right][d c a]$. Isomerisation of BSP-3 to MC has a significant effect on surrounding environment, increasing the entropic contribution to the thermal relaxation process, as seen in experimental results. (a) displays cross section of segment of ionic liquid containing BSP-1. (b) top down view of same segment.

\section{Conclusion}

The application of photochromic compounds as molecular probes has proven effective for the investigation of specific regions within ionic liquids. The integration of functional groups with predetermined polar/non-polar properties allows for the probes 
to be selectively located in a particular region within the ionic liquids based on a mutual attraction of the tethered functional group. Introduction of ultraviolet light and the formation of the MC form of the compounds results in analysis of the region the probe is now located within based upon thermodynamic and kinetic parameters reflected in the thermal relaxation of the compound to its closed form. Polar functionalised derivatives BSP-1 and BSP-2 were believed to interact with the polar domains and possibly the anions within the cavities formed by the phosphonium cations. The extent of the functional group interaction was also observed through the entropies of activation which were found to be generally negative for the polar derivatives. This was due to the fact that the functional groups already associated with polar regions within the ionic liquids and thus the effect of the ring opening/closing of the compound and introduction of a zwitterion had minimal disruption. The opposite was observed for non-polar derivative BSP-3 which had positive entropies of activation. The tetradecane chain is believed to locate the compound in such a way that its ring opening/closing is the primary source of charge-charge interactions and therefore produces system reorganisation upon $\mathrm{MC}$ formation and subsequent relaxation. The ability to predetermine the location of a probe molecule within an ionic liquid now opens up the ability to further study the physico-chemical interactions of certain domains with user specific characteristics but also lead to the development of more advanced materials. 
Acknowledgements

1. K. A. Fletcher, I. A. Storey, A. E. Hendricks, S. Pandey and S. Pandey, Green Chemistry, 2001, 3, 210-215.

2. L. Crowhurst, P. R. Mawdsley, J. M. Perez-Arlandis, P. A. Salter and T. Welton, Phys. Chem. Chem. Phys., 2003, 5, 2790-2794.

3. Z. S. Breitbach and D. W. Armstrong, Anal. Bioanal. Chem. FIELD Full Journal Title:Analytical and Bioanalytical Chemistry, 2008, 390, 1605-1617.

4. S. N. Baker, G. A. Baker, C. A. Munson, F. Chen, E. J. Bukowski, A. N. Cartwright and F. V. Bright, Ind. Eng. Chem. Res. FIELD Full Journal Title:Industrial \& Engineering Chemistry Research, 2003, 42, 6457-6463.

5. P. K. Mandal, A. Paul and A. Samanta, Journal of Photochemistry and Photobiology, A: Chemistry, 2006, 182, 113-120.

6. R. Karmakar and A. Samanta, Chemical Physics Letters, 2003, 376, 638-645.

7. R. Karmakar and A. Samanta, The Journal of Physical Chemistry A, 2002, 106, 6670-6675.

8. K. Iwata, M. Kakita and H.-O. Hamaguchi, Journal of Physical Chemistry B, 2007, 111, 4914-4919.

9. K. Iwata, H. Okajima, S. Saha and H.-O. Hamaguchi, Acc. Chem. Res. FIELD Full Journal Title:Accounts of Chemical Research, 2007, 40, 1174-1181.

10. J. N. C. Lopes, M. F. C. Gomes and A. A. H. Padua, J. Phys. Chem. B FIELD Full Journal Title:Journal of Physical Chemistry B, 2006, 110, 16816-16818.

11. J. N. C. Lopes and A. A. H. Padua, J. Phys. Chem. B FIELD Full Journal Title:Journal of Physical Chemistry $B, 2006,110,3330-3335$. 
12. U. Seiichi, I. Kaoru and A. P. de Silva, Angewandte Chemie International Edition, 2008, 47, 4667-4669.

13. R. Byrne, K. J. Fraser, E. Izgorodina, D. R. MacFarlane, M. Forsyth and D. Diamond, Phys. Chem. Chem. Phys., 2008, 10, 5919-5924.

14. H. Gorner, Phys. Chem. Chem. Phys., 2001, 3, 416-423.

15. V. I. Minkin, Chemical Reviews (Washington, DC, United States), 2004, 104, 2751-2776.

16. R. J. Byrne, S. E. Stitzel and D. Diamond, Journal of Materials Chemistry, 2006, 16, 1332-1337.

17. A. Radu, R. Byrne, N. Alhashimy, M. Fusaro, S. Scarmagnani and D. Diamond, J. Photochem. Photobiol. A-Chem., 2009, 206, 109-115.

18. B. I. Ipe, S. Mahima and K. G. Thomas, J. Am. Chem. Soc., 2003, 125, 7174-7175.

19. K. Tsubaki, K. Mukoyoshi, H. Morikawa, T. Kinoshita and K. Fuji, Chirality, 2002, 14, 713-715.

20. R. Byrne and D. Diamond, Nature Materials, 2006, 5, 421424.

21. Y. Wu, T. Sasaki, K. Kazushi, T. Seo and K. Sakurai, J. Phys. Chem. B FIELD Full Journal Title:Journal of Physical Chemistry B, 2008, 112, 7530-7536.

22. R. Byrne, S. Coleman, K. J. Fraser, A. Raduta, D. R. MacFarlane and D. Diamond, Phys. Chem. Chem. Phys., 2009, 11, 7286-7291.

23. S. Coleman, R. Byrne, S. Minkovska and D. Diamond, Phys. Chem. Chem. Phys. FIELD Full Journal Title:Physical Chemistry Chemical Physics, 2009, 11, 5608-5614.

24. R. Rosario, D. Gust, M. Hayes, F. Jahnke, J. Springer and A. A. Garcia, Langmuir, 2002, 18, 8062-8069.

25. C. P. McCoy, L. Donnelly, D. S. Jones and S. P. Gorman, Tetrahedron Letters, 2007, 48, 657-661. 
26. T. Ramnial, S. A. Taylor, M. L. Bender, B. Gorodetsky, P. T. K. Lee, D. A. Dickie, B. M. McCollum, C. C. Pye, C. J. Walsby and J. A. C. Clyburne, The Journal of Organic Chemistry, 2008, 73, 801-812.

27. C. J. Wohl and D. Kuciauskas, J. Phys. Chem. B FIELD Full Journal Title:Journal of Physical Chemistry B, 2005, 109, 21893-21899.

28. L. Pison, J. N. Canongia Lopes, L. P. N. Rebelo, A. A. H. Padua and M. F. Costa Gomes, The Journal of Physical Chemistry B, 2008, 112, 12394-12400.

29. C. Reichardt, Chemical Reviews (Washington, DC, United States), 1994, 94, 2319-2358.

30. Y. Sueishi, M. Ohcho and N. Nishimura, Bull. Chem. Soc. Jpn. FIELD Full Journal Title:Bulletin of the Chemical Society of Japan, 1985, 58, 2608-2613.

31. M. R. di Nunzio, P. L. Gentili, A. Romani and G. Favaro, ChemPhysChem FIELD Full Journal Title:ChemPhysChem, 2008, 9, 768-775. 